\title{
Antipsychotic withdrawal symptoms: Phenomenology and pathophysiology
}

\author{
S. C. Dilsaver ${ }^{1}$ and N. E. Alessi ${ }^{2}$ \\ Department of Psychiatry, Neuroscience Program, \\ Ohio State University, Columbus, Ohio and \\ 2Diagnostic Research Unit, Child Psychiatry Hospital, \\ Department of Psychiatry, University of Michigan, \\ Ann Arbor, Michigan, U.S.A.
}

\begin{abstract}
The authors review the literature discribing non-dyskinetic antipsychotic withdrawal phenomena. Withdrawal of these agents can cause nausea, emesis, anorexia, diarrhea, rhinorrhea, diaphoresis, myalgia, paresthesia, anxiety, agitation, restlessness, and insomnia. Psychotic relapse is often presaged by increased anxiety, agitation, restlessness and insomnia, but the temporal relationship of these prodromal symptoms to reduction in the dosage or discontinuation of neuroleptics distinguishes them from the effects of abrupt withdrawal.
\end{abstract}

Received May 16, 1987; accepted for publication August 23, 1987

This article reviews the literature on symptoms that follow reductions in the dosage or abrupt discontinuation of neuroleptics. Parallels between the effects of withdrawing these drugs, antiparkinsonian agents, and antidepressants will be presented. The pathophysiology of these withdrawal phenomena will be briefly discussed.

\section{Neuroleptic withdrawal phenomena: \\ Basic questions}

This review will focus on articles describing the development of symptoms within 7 days of the last dose of a neuroleptic (1-18). This minimizes the difficulty in deciding whether symptoms are due to "medical" or "psychiatric" effects of drug withdrawal. Reports suggest that the probability of a previously stable patient experiencing psychotic relapse is minimal in the first 2 weeks after discontinuing neuroleptic (19-28). Thus, those symptoms (such as insomnia, restlessness, decreased appetite, anxiety, mild to moderate agitation, etc.) (29) that develop within the first week of discontinuing the treatment, which might otherwise be regarded as heralding recrudescence, can generally be regarded as due to drug discontinuation.

Four issues should be considered when reviewing the literature devoted to the topic of neuroleptic withdrawal. The first issue is the effect of the concurrent withdrawal of antimuscarinic antiparkinsonian (AMAP) agents. These drugs produce tolerance (30) and their withdrawal can result in symptoms that are similar to those associated with the discontinuation of neuroloptics. Neuroleptics vary in their affinity for muscarinic (mAchR) $(31,32)$ and $\alpha$-adrenergic receptors (33). These could cause withdrawal to affect the autonomic nervous system. Many symptoms produced by the withdrawal of antipsychotics can be due to autonomic dysfunction; thus, the capacities of neuroleptics to produce distress upon their discontinuation can be assessed best if treatment with AMAP agents is controlled. A second issue is the base rate of symptoms associated with the withdrawal of neuroleptics. These symptoms can occur in drug-free population samples. Third, biased observation may result in the over- or underestimation of the frequency of 
withdrawal symptoms. Studies that attempt to characterize withdrawal phenomena without taking base rates into account can only make limited contributions. Studies ascertaining the frequency of symptoms that develop in association with the discontinuation of neuroleptics under double-blind conditions, in experimental (placebo) and control (active medication) groups, would be of particular value in addressing this problem.

Fourth, many mild forms of distress are unreported in the absence of explicit, structured inquiry as to their presence (34). Studies reporting antipsychotic withdrawal symptoms in patients who are evaluated infrequently or in an unstructured manner are apt to underestimate the frequency of symptoms. These issues are addressed in this review.

\section{Antipsychotic withdrawal symptoms}

Symptoms can follow the discontinuation of aliphatic, piperidine and piperazine phenothiazines, thioxanthenes, butyrophenones, and reserpine. The most frequent symptoms are nausea, vomiting, and anorexia. Diaphoresis, headache, insomnia, restlessness, anxiety and agitation are also common. The less frequently noted symptoms are vertigo, alternating feelings of warmth and coldness, myalgia, and tremor. Symptoms generally begin withing 1 to 4 days of withdrawal and abate within 7-14 days. However, there is a report of distress extending into the third or fourth week after the complete discontinuation of haloperidol and benzotropine (8). Symptoms remitted within a week of restarting both medications.

\section{Implications of treatment with and without antiparkinsonian agents}

The simultaneous withdrawal of AMAP agents and neuroleptics may intensify the severity of those symptoms associated with the withdrawal of the latter. Adaptation to antimuscarinic drugs includes mAchR up-regulation $(35,36)$ and the development of supersensitivity (37-39) by cholinoceptive neurons. These changes provide a basis for the occurrence of cholinergic rebound upon drug discontinuation. These states include a flu-like syndrome, myalgia, diaphoresis, malaise, rhinitis, parasthesias, gastrointestinal distress, headaches, anxiety, insomnia, terrifying dreams, fatigue, dysphoria, and the rebound exacerbation of motor system dysfunction in patients treated with these agent for Parkinson's disease or neuroleptic-induced extrapyramidal system dysfunction (37). Simpson et al. (10) reported that none of the 10 subjects withdrawn from trifluoperazine alone (mean dose $=123 \mathrm{mg} /$ day/ patient, range $=20-480 \mathrm{mg} /$ day) developed withdrawal symptoms. However, when the study was modified so that each patient received benzotropine methanesulphat ( $2 \mathrm{mg}$ twice or 3 times daily) and was maintained on this regimen for 1 month prior to the abrupt withdrawal of both agents, 3 subjects developed withdrawal symptoms. In a related study, these authors abruptly withdrew patients $(n$ $=8$ ) from butaperazine and benzotropine or from butaperazine alone $(n=9)$. The latter group continued to receive benzotropine. Only two $(22 \%)$ patients who continued to receive the AM-AP agent developed withdrawal symptoms but $(75 \%)$ of those abruptly withdrawn from both drugs developed symptoms. Similarly, Bategay (1) reported that 55 of 81 subjects $(68 \%)$ abruptly withdrawn from neuroleptics or neuroleptics and AM-AP agents simultaneously developed withdrawal symptoms $(P<0.01)$. However, those subjects withdrawn from neuroleptics alone (35 of 64; $54 \%$ ) did not exhibit an increased frequency of symptoms relative to this, whereas subjects withdrawn from both types of drugs ( 20 of $23 ; 87 \%$ ) did.

One strategy used to address the effects of withdrawing neuroleptics in subjects being treated with AMAP agents is to continue treatment with the former while withdrawing the latter. Two studies have employed this strategy, and in these 37 or 77 patients $(48 \%)$ are noted to have developed withdrawal symptoms $(4,10)$. Four reports $(1,3,5,7)$ involve large samples in which it is not mentioned whether subjects were withdrawn from neuroleptics and AMAP agents concurrently. Should he absence of a specific statement on this be interpreted to mean that AMAP agents were not simultaneously withdrawn with neuroleptics, it would follow that 84 of 216 subjects $(39 \%)$ explicitly stated or implied not to have been withdrawn from an AMAP agent developed symptoms $(1,3-5,7,9,10)$. However, the fact that it is usually not mentioned whether an AMAP agent is or is not simultaneously withdrawn suggests that the importance of this factor is not appreciated. 
Base rate of symptoms associated with the withdrawal of neuroleptics

Reidenberg \& Lowenthal (40) measured the frequency of 25 symptoms often considered to be side-effects of medication in $\mathbf{1 7 5}$ drug-free normal subjects. Twelve of these symptoms (fatigue, poor concentration, irritability, insomnia, loss of appetite, nausea, vomiting, diarrhea, dizziness, headaches, pain in muscles, and excessive sleepiness) are associated with the withdrawal of neuroleptics. The base rate of those symptoms were: fatigue, $37 \%$, inability to concentrate, $27 \%$; irritability, $17 \%$; insomnia, $10 \%$; loss of appetite, $6 \%$; nausea, $2 \%$; vomiting, $0 \%$; diarrhea, $2 \%$; dizziness, $5 \%$; headaches, $13 \%$; pain in muscles, $11 \%$; and excessive sleepiness, $23 \%$. Only $18 \%$ of these subjects reported not having had any of these symptoms. Similarly, Wolf et al. (41) found that the treatment of normal subjects with placebo was associated with "adverse" effects that are often associated with drug treatment or withdrawal. These findings establish that symptoms known to be side-effects and withdrawal effects occur in the general population at significant frequencies. Therefore, studies that attempt to measure neuroleptic withdrawal phenomena without taking this into account are prone to an overestimation of the prevalence or frequency of antipsychotic withdrawal symptomatology.

Lacoursiere et al. (7) attempted to address this issue by measuring the frequency of symptoms associated with antipsychotic withdrawal before and after the discontinuation of drugs. Eleven percent $(11 \%)$ of their subjects had "withdrawal-like" symptoms prior to drug discontinuation and $38 \%$ had symptoms afterwards $(P<0.05)$. Thus, while symptoms associated with the withdrawal of neuroleptics are not specific, the withdrawal of these agents appears to increase the frequency of these symptoms.

\section{Pathophysiology}

Antipsychotic agents bind to dopamine (42), muscarinic $(3,32)$ and adrenergic $(33)$ receptors in vit$r o$ and produce antidopaminergic, antimuscarinic, and antiadrenergic effects in vivo. Drug-induced supersensitization of dopaminergic and cholinoceptive neurons can account for many of the symptoms following the discontinuation of neuroleptics. Antipsychotic drugs possess antiemetic properties due to their antidopaminergic actions within the chemotactic trigger zone (43). Chronic treatment with neuroleptics might result in supersensitivity to dopamine (44) or up-regulation of dopamine receptors (45) within this neuronal population and gastrointestinal symptoms (nausea, vomiting, and the loss of appetite) noted with antipsychotic withdrawal. Cholinergic overdrive mimics some of the symptoms associated with the discontinuation of antipsychotic drugs. Cholinesterase inhibitors produce a syndrome characterized by lassitude, irritability, dysphoria, emotional lability, restlessness, slowed thought production, insomnia, nausea, vomiting, and diarrhea (39). However, a simple cholinergic overdrive hypothesis would not take into account the profound effects of neuroleptics on other systems.

Antipsychotic agents vary in their affinity for the mAchR $(31,32)$. Lacoursiere et al. (7) attempted to address the significance of this by dividing patients $(n=48)$ into groups treated with "autonomic" (aliphatic or piperidine phenothiazines, or chlorprothixenes), or "non-autonomic" neuroleptics (piperazine phenothiazines, butyrophenones, or thiothixene). Type of neuroleptic was not associated with an increased frequency of withdrawal symptoms in this study. Sample size may have limited the sensitivity of this study. An analysis based on a compilation of reported cases did suggest that drugs with greater antimuscarinic affects are more apt to produce withdrawal symptoms (16).

\section{Similarities between antipsychotic and antidepressant withdrawal symptoms}

The discontinuation of tricyclic antidepressants (TCA) produces malaise, myalgia, anergy, diaphoresis, rhinitis, flashes of chills and warmth, parasthesias, headaches, nausea and vomiting, anorexia, gastrointestinal pain, diarrhea, initial and middle insomnia, fatigue, drowsiness, anxiety, agitation, irritability, and depressed mood $(37,39)$. These symptoms also have their onset 1-2 days after the last dose of medication or in the course of a gradual taper and are responsive to centrally active antimuscarinic agents (37).

Structurally and pharmacologically, at least with respect to affinity for $\mathrm{mAchRs}$ and $\alpha$-adrenergic receptors, TCA and aliphatic and piperdine phenothiazines are similar. However, TCAs do not pos- 
sess affinity for dopamine receptors. In contrast, piperazine phenothiazines and haloperidol have high affinity (42) for dopamine receptors and relatively low affinity for $m \operatorname{Ach} R(31,32)$. The affinity of antagonists (46) for the $\mathrm{mAchR}$ correlates with their propensity to produce physiological $(47,48)$ and biochemical (49) evidence of receptor blockade. It is conceivable that TCA and neuroleptics affect the same neural mechanisms and thus produce similar withdrawal phenomena; however, the same withdrawal symptom might also be produced via different mechanisms.

Luchins et al. (16) concluded that cholinergic rebound does not account for haloperidol-associated withdrawal phenomena. Binding data support this conclusion since haloperidol binds weakly to muscarinic receptors. Dopamine and dopaminergic agonists generally inhibit the release of acetylcholine, and the immediate result of administering a neuroleptic is increased release of acetylcholine (50-52). Acute and chronic effects, such as catalepsy (53) may be due to differing influences of these two modes of administration on muscarinic mechanisms. However, chronic treatment with haloperidol and piperazine phenothiazines may actually inhibit the release of acetylcholine due to the induction of supersensititvity to dopamine (54). This could decrease the avilability of acetylcholine on the post-synaptic side of the synapse, and thus supersensitize cholinoceptive neurons. The literature on drugs affecting supersensitivity of cholinergic mechanisms was recently reviewed by the author (55). Further, Shalaby \& Spear (56) observed that the chronic administration of haloperidol to pregnant rats resulted in supersensitivity to the cataleptic effects of arecoline on postnatal day 65. Miller \& Freidhoff (57) recently reported that prenatal exposure to haloperidol or ( + )-butaclamol increased the density of mAchRs and the activity of choline acetyltransferase in the striatum postnatally in rats. These findings suggest that under certain circumstances, treatment with haloperidol can supersensitize and up-regulate a cholinergic network.

\section{Summary}

Reductions in the dosage or abrupt discontinuation of neuroleptics can produce symptoms that generally have their onset within $48 \mathrm{~h}$ of the last dose, and rarely after the first week. These symptoms may be more severe and frequent when AMAP agents are simultaneously discontinued. Antipsychotic withdrawal symptoms can mimic symptoms marking the early stages of psychotic relapse. However, the recurrence of psychotic symptoms is rare in the first week after drug discontinuation. A clinically stable patient for whom withdrawal of neuroleptics is indicated who becomes anxious, agitated, restless, and experiences insomnia within the first few days after discontinuing treatment with a neuroleptic is more apt to be suffering from an acute withdrawal syndrome than to be in the process of relapse.

Antipsychotic withdrawal symptoms may not be reported unless the clinician specifically inquires as to their presence. Further, the time frame over which they are apt to occur is of particular relevance. A patient whose last dose of a neuroleptic is 14 days prior to the next clinic visit may report no symptoms for the preceding week despite having had symptoms the first week after withdrawal. This issue can be addressed in future studies by using structured means of frequent data collection. Clinician and patient-completed rating scales standardized in normal samples should be used to measure the frequency of specific symptoms at various points before and after drug withdrawal.

\section{Acknowledgement}

This study was supported in part by Physician Scientist Development Award MH 0055302.

\section{References}

1. Bategay R. Drug dependence as a criterion for differention of psychotropic drugs. Compr Psychiatry 1966: 7:501-509.

2. Brooks GW. Withdrawal from neuroleptic drugs. Am J Psychiatry 1959:16:931-932.

3. Gallant DM, Edwards CG, Bishop MP, Galbraith GC. Withdrawal symptoms after abrupt cessation of antipsychotic compounds: clinical, confirmation in chronic schizophrenics. Am J Psychiatry 1964:121.491-493.

4. Greenberg LM, Roth S. Differential effects of abrupt versus gradual withdrawal of chlorpromazine in hospitalized chronic schizophrenic patients. Am J Psychiatry 1966: 123:221-226.

5. Haden P. Gastrointestinal disturbances associated with withdrawal of ataractic drugs. Can Med Assoc J 1964:91:975.

6. Kalman T, Warner GM. Protracted vomiting following abrupt cessation of psychotropics. Can Psychiatr Assoc J 1978: $23.163-165$. 
7. Lacoursiere RB, Spohn HE, Thompson K. Medical effects of abrupt neuroleptic withdrawal. Compr Psychiatry 1976: 17:285-294.

8. Liebermann J. Cholinergic rebound in neuroleptic withdrawal syndromes. Psychosomatics 1981:22:253-254.

9. Melnytt WT, Worthington AG, Laverty. Abrupt withdrawal of chlorpromazine and thioridazine from schizophrenic patients. Can Psychiatr Assoc 1965.6:347-351.

10. Simpson GM, Amin M, Konz E. Withdrawal effects of phenothiazines. Compr Psychiatry 1965:6:347-351.

11. Yepes LE, Winsberg BG. Vomiting during neuroleptic withdrawal in children. Am J Psychiatry 1977:134:574.

12. Dilsaver SC, Leckrone J, Greden JF. Cholinergic syndrome from psychotropic withdrawal in a marijuana abuser. Psychosomatics 1984:25:132-134.

13. Eppel AB, Mishra R. The mechanism of neuroleptic withdrawal. Can J Psychiatry 1984:29:508-509.

14. Gardos G, Cole JO, Tarsy D. Withdrawal syndromes associated with antipsychotic drugs. Am I Psychiatry 1980: 137:1395-1398.

15. Judah LN, Josephs ZM, Murphree OD. Results of simultaneous abrupt withdrawal of ataraxics in 500 chronic psychotic patients. Am J Psychiatry 1961:118:156-158.

16. Luchins DJ, Freed MH, Wyatt RJ. The role of cholinergic supersensitivity in the medical symptoms associated with withdrawal of antipsychotic drugs. Am J Psychiatry 1980:137:1395-1398.

17. Mitchell JE. Discontinuation of antipsychotic drug therapy. Psychosomatics 1981:22:241-247.

18. Chouinard G, Bradwejn J, Annable L, Jones BD, RossChouinard A. Withdrawal symptoms after chronic treatment with low potency neuroleptics. J Clin Psychiatry 1984:45:500-502.

19. Caffey EM, Diamond LS, Frank TC, et al. Discontinuation or reductions of chemotherapy in chronic schizophrenics. J Chronic Dis 1964: 17:347-358.

20. Diamond LS, Marks JB. Discontinuance of tranquilizers among chronic schizophrenic patients receiving maintenance dosage. J Nerv Ment Dis 1960:131:247-251.

21. Freeman LS, Alson E. Prolonged withdrawal of chlorpromazine in chronic patients. Dis Nerv System 1902:23:522-525.

22. Good WW, Sterling M, Haltzman WH. Termination of chlorpromazine with schizophrenic patients. Am J Psychiatry 1958: 115:433-448.

23. Morton MR. A study of withdrawal of chlorpromazine in chronic schizophrenia. Am J Psychiatry 1968:124:15851588.

24. Olson GW, Peterson D. Sudden withdrawal of tranquilizing drugs from chronic psychiatric patients. J Nerv Ment Dis 1960:131:252-255.

25. Whittaker CB, Hay RM. Withdrawal of perphenazine in chronic schizophrenia. Br J Psychiatry 1964:109:422-427.

26. World PN. A long-term evaluation of chlorpromazine in six chronic shizophrenic patients. J Nery Ment Dis 1980:130:151-154.

27. Rothestein C, Zeltzerman I, White HR. Discontinuation of maintenance dosages of ataractic drugs on a psychiatric continued treatment ward. J Nerv Ment Dis 1962:134:550-560.

28. Rothstein C. An evaluation of the effects of discontinuation of chlorpromazine. N Engl J Med 1960:262:67-69.
29. Docherty JP, Van Kammen DP, Siris SG, Marden SR. Stages of schizophrenic psychosis. Am J Psychiatry 1978:135.420425.

30. Dilsave SC. Antimuscarinic agents as substances of abuse. J Clin Psychopharmacol. In press.

31. Snyder S, Greenberg D, Yommura HI. Antischizophrenic drugs and brain cholinergic receptors. Arch Gen Psychiatry 1974:31:58-61.

32. Miller RJ, Hilly CR. Antimuscarinic properties of neuroleptics and drug induced parkinsonism. Nature 1974:248:596597.

33. Peroutka SJ, Snyder SJ. Relationship of $\alpha$-receptors neuroleptic drug effects at brain dopamine, serotomin alpha adrenergic, and histamine receptors to clinical potency. Am J Psychiatry 1980:136:1318-1322.

34. Gammon GD, Jolm K, Rothblum ED, et al. Use of structured interview to identify bipolar disorder in adolescent patients: frequency and manifestation of the disorder. Am J Pscychiatry 1983: 140:543-547.

35. Ehlert FJ, Roeske WR, Yamamura HI. The nature of muscarinic binding. In: Iversen LL, Iveren SD, Snyder SN, eds. Handbook of psychopharmacology. Vol 17. New York: Plenum, 1983

36. Takeyasu K, Uchida $S$, Nogechi $Y$, et al. Changes in brain muscarinic acetylcholine receptors and behavioral responses to atropine and morphine in chronic atropine treated rats. Life Sci 1979:25:585-592.

37. Dilsaver SC, Greden JF. Antidepressant withdrawal phenomena. Biol Psychiatry 1984: 19:237-256.

38. Dilsaver SC, Alessi NE, Snider RM. Amitriptyline supersensitizes a central cholinergic mechanism. Biol Psychiatry 1987:22:495-507

39. Dilsaver SC, Kronfol Z, Sackellares JC, Greden JF. Antidepressant withdrawal syndromes: evidence supporting the cholinergic overdrive hypothesis. J Clin Psychopharmacol 1983: 3:157-164.

40. Reidenberg MM, Lowenthal DT. Adverse nondrug reactions. N Engl J Med 1968: 279:678-679.

41. Wolf S, Pinsky MA. Effects of placebo administration and occurrence of toxic reactions. JAMA 1954:155:339-343.

42. Lee $T$, Leemen $P$. Correlation of antipsychotic drug potency and neuroleptic receptor inhibition in post-mortem human brains. Soc Neurosci 1979:5:653.

43. Innes IR, Nickerson M. Atropine, scopolamine, and related antimuscarinic drugs. In: Goodman LS, Gilman A, eds. The pharmacological basis of therapoeutics, 5 th edit. New York: MacMillan, 1975:161.

44. Clow A, Theodoru A, Jenner P, Marsden CD. Cerebral dopamine function in rats following withdrawal from one year of continuous neuroleptic administration. Eur $\mathbf{J}$ pharmacol 1980:63:145-157.

45. Burt DR, Creese I, Snyder SH. Antischizophrenic drugs: chronic treatment elevates dopamine receptor binding in brain. Science 1976:196:325-338.

46. Snyder SH, Yamamura HI. Antidepressants and the muscarinic acetylcholine receptor. Arch Gen Psychiatry 1977:34:236-239.

47. Blackwell B, Stefopoulos A, Enders P, Kuzma R, Adolphe A. Anticholinergic activity of two tricyclic antidepressants. Am I Psychiatry 1978: 135:722-4. 
48. Szabadi P, Baszner P, Bradshaw CM. The peripheral anticholinergic activity of tricyclic antidepressants. Comparison of amitriptyline and desipramine in human volunteers. $\mathrm{Br} J$ Psychiatry 1980:137:433-439.

49. Richelson $E$, Dininetz-Romero $S$. Blockade by psychotropic drugs of the muscarinic acetylcholine receptor in cultured nerve cells. Biol Psychgiatry 1977: 12:771-785.

50. Waldmeier P. Biphasic effects of some dopamine agonists on striatal acetylcholine concentration. Eur I Pharmacol 1983:90:115-120.

51. Rommelspacher H, Kuhar MJ. Effects of dopaminergic drugs and acute medial forebrain bundle lesions on striatal acetylcholine levels. Life Sci 1975:16.65-70.

52. Scatton B. Effect of dopamine agonists and neuroleptic agents on striatal acetylcholine transmission in the rat: evidence against dopamine receptor multiplicity. J Pharmacol Exp Ther 1982a:220:197-202.

53. Klemmen WR. Evidence for a cholinergic role in haloperidol-induced catalepsy. Psychopharmacology (Berlin) 1985:895:139-142.

54. Choi RL, Roth RH. Development of supersensitivities of apomorphine-induced increases in acetylcholine levels and stereotype after chronic fluphenazine treatment. Neuropharmacology 1978:17:59-64.
55. Dilsaver SC. Substance abuse and affective disorders: an integrative model? J Cliln Psychopharmacol 1987: 7:1-10.

56. Schalaby A, Pitia, Spear L. Chronic administration of haloperidol during development: later psychopharmacological responses to anomorphine and arecoline. Pharmacol Biochem Behav 1980:135:685-690.

57. Miller JC, Friedhoff AJ. Prenatal neuroleptic exposure alters postnatal striatal cholinergic activity in the rat. Dev Neurosci 1986:8:161-166.

Addresss

Steven C. Dilsaver, M.D.

Department of Psychiatry

Neuroscience Program

Ohio State University

$473 \mathrm{~W}, 12$ th Ave.

Columbus, Ohio 43210-1228

U.S.A. 